\title{
DIFFERENCES IN ADRENAL MORPHOLOGY IN MALE DARK AGOUTI, SPRAGUE-DAWLEY AND WISTAR RATS
}

\author{
Jenny M. WILKINSON* ${ }^{*}$ S. HALLEY and P. A. TOWERS \\ School of Biomedical Sciences, Charles Sturt University, Wagga Wagga, NSW 2678, \\ Australia
}

(Received August 3, 1998; accepted February 18, 1999)

\begin{abstract}
There is little published information describing the differences in adrenal structure between strains of a single species despite quite well known functional differences. In this paper we report morphological differences in the adrenal glands between three strains of laboratory rat; Dark Agouti (DA), Sprague-Dawley (SD) and Wistar (W). Significant differences in adrenal weights (as a percentage of body weight) were not detected between any of the groups. While there were no significant differences in the volume of medullary or zonae glomerulosa or fasciculata tissue, the volume fraction for the zona reticularis was significantly smaller in DAs compared to the other strains. The functional significance of these differences is unknown. However, it is suggested that the reduced volume of zona reticularis tissue may contribute to a reduced capacity for glucocorticoid synthesis or storage.
\end{abstract}

Key words: Rat, adrenal cortex, Dark Agouti, Sprague-Dawley, Wistar

A functional adrenal gland is essential for life as it releases a number of essential hormones including corticosteroids, adrenaline and aldosterone. It is now recognised that there are species differences in adrenal structure and function, particularly in the distribution and concentration of steroidogenic enzymes within the adrenal cortex (Ishimura and Fujita, 1997; Murray and Pharrama, 1997). In addition within laboratory rats, adrenal morphology differs between sexes with females typically having larger adrenals and increased zona fasciculata (ZF) cell size compared to males (Malendowicz, 1980; Majchrzak and Malendowicz, 1983). Furthermore, Malendowicz (1987) found differences between rat strains (Chbb Thomm, CFY \& Wistar) in both adrenal weight and volumes of ZF and zona reticularis (ZR). Strain differences are also seen in corticosterone and corticosterone-binding globulin levels (Vinson et al., 1978; Dhabhar et al., 1993) and responsiveness to stressors (Gilad and Jimerson, 1981; Gomez et al., 1998).

*E-mail: jwilkinson@csu.edu.au; Fax: 61269332589 
In this paper we describe an investigation into whether differences in adrenal gland morphology exist in males of three rat strains - Dark Agouti, Sprague-Dawley and Wistar.

\section{Materials and methods}

Six months old Dark Agouti $(n=8)$, Sprague-Dawley $(n=4)$ and Wistar $(\mathrm{n}=9)$ male rats were provided with dry food pellets (YS Feeds Mouse Breeder 602) and water ad libitum with animal house conditions maintained at $20 \pm 1.5^{\circ} \mathrm{C}$, $56 \pm 9.6 \%$ relative humidity, and a $12 \mathrm{~h}: 12 \mathrm{~h}$ photoperiod. Euthanasia was by intraperitoneal injection of sodium pentobarbitone $(60 \mathrm{mg} / \mathrm{kg})$. Animals were weighed, the adrenal glands removed, trimmed of surrounding fat and connective tissues and weighed. The glands were immersion fixed in Bouin's fixative overnight followed by routine processing and embedding in paraffin wax. Serial sections $(8 \mu \mathrm{m})$ were cut using a rotary microtome and the sections mounted onto gelatine-coated microscope slides. Sections were stained with Mayer's haematoxylin and eosin. Ethical approval for this project was gained from the Charles Sturt University Animal Care and Ethics Committee (protocol 97/048 \& 98/015).

Stereological analysis was performed using the principles of unbiased stereology as described by Howard and Reed (1998). For cortex and medulla volumes and volume fraction measurements every tenth section was assessed using Grid P5 (Howard and Reed, 1998). For cortex zonal analysis the median section of the gland was used. Statistical comparisons of stereological measures were done using a one-way ANOVA.

\section{Results}

The results for absolute and relative adrenal weights are presented in Table 1. Adrenal glands from DA rats were found to be significantly smaller than those from Wistar rats. There were no significant differences in adrenal weight between the SD and Wistar animals or between the SD and DA animals.

Cortex and medulla volume fraction (\%) and gland volume for the three strains are shown in Fig. 1. There was a significantly larger $(p<0.001)$ volume fraction of medullary tissue and reduced cortical tissue in the DA animals compared to either the SD or Wistar animals. Volume fraction of medullary tissue in the SD and Wistars was approximately $50 \%$ of that in the DAs (Fig. 1A). When gland volume $\left(\mathrm{mm}^{3}\right)$ was calculated there was no significant difference between the volume of the medulla in each of the three strains (Fig. 1B) but there was a significant difference between the cortical volume in the DA and the SDs $(p<$ $0.01)$ and between the DAs and the Wistars $(p<0.001)$. Total gland volume was only significantly different between DA and Wistar animals $(p<0.001)$. 
Table 1

Adrenal weights and volume fraction (\%) for male DA, SD and Wistar rats

\begin{tabular}{lccc}
\hline & Dark Agouti & Sprague-Dawley & Wistar \\
\hline Adrenal weight (mg) & $16 \pm 1.0^{\mathrm{b}}$ & $20 \pm 1.5$ & $24 \pm 1.0^{\mathrm{b}}$ \\
Relative adrenal weight (mg/100g body weight) & $4.1 \pm 0.3^{\mathrm{a}}$ & $4.2 \pm 0.3$ & $5.9 \pm 0.4^{\mathrm{a}}$ \\
Volume fractions (\%) & & & \\
$\quad$ Zona glomerulosa & $15.7 \pm 1.0$ & $14.8 \pm 1.5$ & $13.0 \pm 0.9$ \\
$\quad$ Zona fasciculata & $25.0 \pm 1.1$ & $23.5 \pm 1.0$ & $23.9 \pm 1.0$ \\
$\quad$ Zona reticularis & $30.1 \pm 1.6^{\mathrm{c}}$ & $42.8 \pm 0.4$ & $46.1 \pm 2.0$ \\
$\quad$ Medulla & $29.1 \pm 1.1^{\mathrm{c}}$ & $18.9 \pm 1.1$ & $17.0 \pm 1.1$ \\
\hline
\end{tabular}

Results are expressed as mean \pm SEM. Significant differences indicated by superscripts $-{ }^{a} \mathrm{p}<0.01$ DA vs. Wistar; ${ }^{b} p<0.001$ DA vs. Wistar; ${ }^{c} p<0.001$ DA vs. both SD \& Wistar
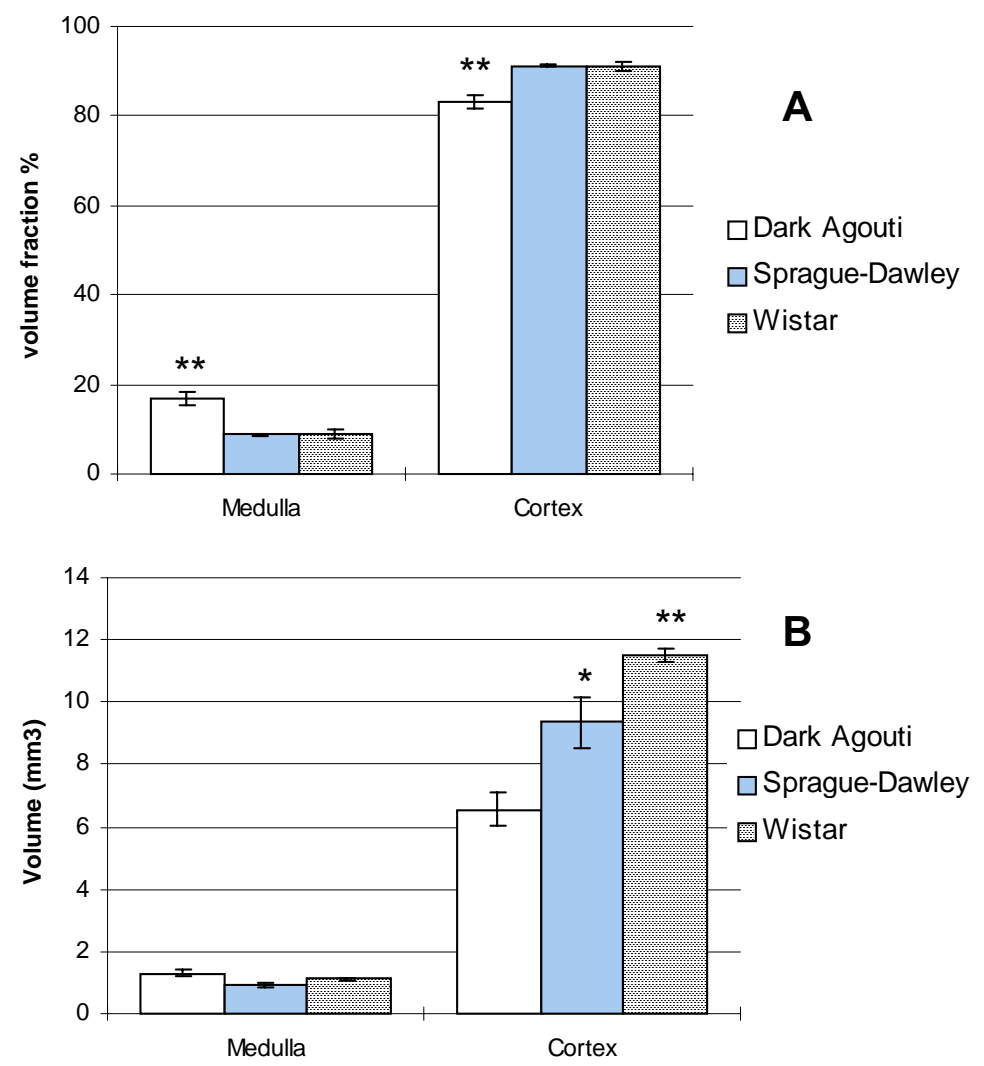

Fig. 1. Stereological analysis of adrenal medulla and cortex in DA, SD and Wistar male rats. Data expressed as mean \pm SEM. A) Volume fractions (\%) of adrenal medulla and cortex. ${ }^{* *}$ DA vs. both SD \& Wistar; $\mathrm{p}<0.001 ; \mathrm{B})$ Adrenal medulla and cortex volume $\left(\mathrm{mm}^{3}\right)$. "DA vs. SD; $\mathrm{p}<0.01$;

${ }^{* *}$ DA vs. Wistar; $\mathrm{p}<0.001$ 
To determine the particular zone in which differences lay, volume fractions of each cortical zone were calculated using median sections of the gland. There were no differences in the volume fractions of the three zones in the Wistar and SD animals (Table 1). However the volume fraction for the ZR was significantly smaller in the DA animals compared to the other strains $(p<0.001)$ and the volume fraction of the medulla was significantly higher in the DAs than the SDs or Wistars $(\mathrm{p}<0.001)$.

\section{Discussion}

In this paper we report the differences in adrenal morphology in males of three rat strains. DA animals were found to have significantly smaller adrenals than Wistar animals, a difference that could not be accounted for by the smaller body size of the DA rats. Stereological analysis of whole glands revealed that the DA animals had almost double the amount of medullary tissue relative to cortical tissue compared with the other strains. When expressed as a volume we found that the volume of medullary tissue in the three strains was not significantly different but that the DA animals had significantly less cortical tissue. The origin of the differences in volume of cortical tissue in the DA rats was shown to be in the ZR, which was significantly smaller than that in SD or Wistar rats. The changes in cortical zone size do not appear to be related to a chronic stress response as only one zone was affected whereas in the stress response cells of both the ZF and ZR increase their lipid content and zonal size (Nussdorfer, 1986).

The organisation of the adrenal gland into zones is determined by the collagen fibrillar network and by the vascularity of the gland. In rats the ZR cells are unable to synthesise androgens and the ZF and ZR act as a single functional unit secreting corticosterone. West and Bassett (1993) reported an inverse relationship between gland activity and size of the inner cortex which was related to vascular damming in the cortico-medullary junction (or ZR) and not to any change in cell size or number. These authors suggest that vascular damming allows storage of corticosterone in the vascular spaces and provides a mechanism to facilitate rapid corticosterone release in response to corticotropin (West and Bassett, 1993; Bassett and West, 1997). We suggest that the reduced size of the ZR in DA rats may be a result of reduced vascular spaces or cell number.

The functional significance of the strain differences described in this paper are unknown, however it might be speculated that the decreased amount of inner cortex tissue in addition to, or as a result of decreased vascular spaces, may result in lowered basal levels of corticosterone secretion. We were unable to find any data reporting corticosterone, corticotropin or corticotropin releasing factor levels in this strain. Further electron microscopic and biochemical studies will elucidate the origin of the reported strain differences. 


\section{Acknowledgements}

The authors wish to thank Val McGuire for care of the animals used in this study. This work was funded by a Charles Sturt University Rural Biomedical Research Group grant to JW.

\section{References}

Bassett, J. R. and West, S. H. (1997): Vascularisation of the adrenal cortex: Its possible involvement in the regulation of steroid hormone release. Microsc. Res. Tech. 36, 546-557.

Dhabhar, F. S., McEwen, B. S. and Spencer, R. L. (1993): Stress response, adrenal steroid receptor levels and corticosteroid-binding globulin levels - a comparison between Sprague-Dawley, Fischer 344 and Lewis rats. Brain Res. 616, 89-98.

Gilad, G. M. and Jimerson, D. C. (1981): Modes of adaptation of peripheral neuroendocrine mechanisms of the sympatho-adrenal system to short-term stress as studied in two inbred rat strains. Brain Res. 206, 83-89.

Gomez, F., De Kloet, E. R. and Armario, A. (1998): Glucocorticoid negative feedback on the HPA axis in five inbred rat strains. Am. J. Physiol. 274, (2 Pt 2): R420-427.

Howard, C. V. and Reed, M. G. (1998): Unbiased stereology. Three-dimensional measurement in microscopy. Microscopy Handbooks 41. Bios Scientific. Oxford, UK.

Ishimura, K. and Fujita, H. (1997): Light and electron microscopic immunohistochemistry of the localisation of adrenal steroidogenic enzymes. Microsc. Res. Tech. 36, 445-453.

Majchrzak, M. and Malendowicz, L. K. (1983): Sex differences in adrenocortical structure and function. XII. Stereologic studies of rat adrenal cortex in the course of maturation. Cell Tiss. Res. 232, 457-469.

Malendowicz, L. K. (1980): Sex differences in adrenocortical structure and function. VI. Longterm effect of gonadectomy and testosterone or estradiol replacement on rat adrenal cortex. Endokrinologie 75, 311-323.

Malendowicz, L. K. (1987): Sex differences in adrenocortical structure and function. XXIV. Comparative morphometric studies on adrenal cortex of intact male and female rats of different strains. Cell Tiss. Res. 249, 443-449.

Murray, S. A. and Pharrama, S. Y. (1997): Comparison of gap junction expression in the adrenal medulla. Microsc. Res. Tech. 36, 510-519.

Nussdorfer, G. G. (1986): Cytophysiology of the adrenal cortex. Int. Rev. Cytol. 98, 1-405.

Vinson, G. P., Whitehouse, B. J. and Kolesnikova, L. V. (1978): The effect of sex and strain of rats on in vitro response of adrenocortical tissue to ACTH stimulation. J. Steroid Biochem. 9, $553-560$.

West, S. H. and Bassett, J. R. (1993): Diurnal variation in adrenal gland freshweight due to vascular damming: A possible role in corticosterone storage. Tissue Cell 25, 495-503. 